\title{
Effects of the epigenetic drug MS-275 on the release and function of exosome-related immune molecules in hepatocellular carcinoma cells
}

\author{
Wenhua Xiao ${ }^{1 * \dagger}$, Weiwei Dong ${ }^{1 \dagger}$, Caihong Zhang ${ }^{2}$, Gaowa Saren ${ }^{3}$, Paili Geng ${ }^{2}$, Huixia Zhao ${ }^{1}$, Quiwen Li ${ }^{1}$,
} Jianhua Zhu', Guanghui Li', Shufang Zhang ${ }^{1}$ and Ming Ye ${ }^{1}$

\begin{abstract}
Background: Tumor-derived exosomes have been viewed as a source of tumor antigens that can be used to induce anti-tumor immune responses. In the current study, we aim to investigate the regulatory effect of the epigenetic drug MS-275 on hepatoma G2 (HepG2) cell-derived exosomes, especially for their immunostimulatory properties and alteration of some non-specific immune protein expression, such as heat shock protein (HSP) 70, major histocompatibility complex (MHC) class I polypeptide-related sequence A (MICA) and MICB.

Methods: MS-275 was used to modulate the secretion of exosomes in human HepG2 cells, and exosomes from untreated HepG2 cells served as negative controls. RT-PCR was used to test the expression of HSP70, MICA and MICB in HepG2 cells. Immunogold labeling of exosomes and western blotting analysis were carried out to compare the expression of HSP70, MICA and MICB proteins in exosomes with or without MS-275 treatment. A natural killer (NK) cell cytotoxicity assay and peripheral blood mononuclear cell (PBMC) proliferation assay were used to evaluate the effect of MS-275 on the immunostimulatory ability of exosomes.

Results: Immunogold labeling and western blot analysis showed that modification of MS-275 increased the expression of HSP70 and MICB in exosomes. RT-PCR showed the mRNA levels of HSP70 and MICB were upregulated in HepG2 cells and were consistent with their protein levels in exosomes. The exosomes modified by MS-275 could significantly increase the cytotoxicity of NK cells and proliferation of PBMC $(P<0.05)$.

Conclusions: The non-specific immune response of exosomes derived from HepG2 cells could be enhanced with treatment by the histone deacetylase inhibitor (HDACi) drug MS-275; this could provide a potential tumor vaccine strategy against liver cancer.
\end{abstract}

Keywords: Exosomes, HepG2, HSP70, MICA, MICB, NK cell

\section{Background}

Exosomes are small membrane-bound particles with a diameter of 30 to $100 \mathrm{~nm}$; exosomes can be released from both normal and diseased cells, such as neoplastic cells, to the blood and other bodily fluids [1-3]. They contain signal proteins and/or peptides, microRNAs, mRNAs, and lipids $[4,5]$, and, after release from diseased or normal cells, some exosomes are transported to distant sites by blood [6,7]. Studies have shown that exosomes secreted by tumor cells have immunosuppressive and pro-cancer activities [3,8];

\footnotetext{
* Correspondence: wenhuaxiao77@163.com

${ }^{\dagger}$ Equal contributors

${ }^{1}$ The First Affiliated Hospital, PLA General Hospital, Fucheng Road 51, Beijing, China Full list of author information is available at the end of the article
}

both in vivo and in vitro evidence has showed that exosomes derived from tumor cells can augment an antitumor response $[9,10]$. However, the capacity of tumorderived exosomes in the cellular immune response against tumors is limited by numerous factors, including the heterogeneity of tumor antigens, the type and molecular chaperone of immune molecules in different tumor cells, the insufficient expression of tumor-associated antigens and immune molecules, the inhibited immune cell proliferation by tumor-derived exosomes, and downregulated NKG2D ligand expression at the tumor cell surface which influences the activity of natural killer (NK) cells and their cytotoxicity to tumor cells [11-13]. 
MS-275 is one of the histone deacetylase inhibitor (HDACi) drugs which is commonly used as an epigenetic drug to upregulate tumor specific antigens such as human leukocyte antigen-I, human leukocyte antigen-II, co-stimulatory molecule B7, and immune adhesion molecules. MS-275 could enhance the specific and nonspecific anti-tumor immune reaction. In this study, we attempted to explore the effects of MS-275 on the release and function of exosome-related immune molecules in hepatoma G2 (HepG2) cells.

\section{Methods}

Preparation of peripheral blood mononuclear cells and natural killer cells

Following approval from our hospital ethics committee, $20 \mathrm{ml}$ peripheral blood samples were collected into a 50-ml CPT cell preparation tube (Becton Dickinson, Cowley, UK) from healthy donors who signed consent forms. Peripheral blood mononuclear cells (PBMCs) were isolated by Ficoll gradient centrifugation as previously described [14]. After washing in PBS, cells were resuspended in RPMI 1640 medium at a concentration of $1 \times 10^{7} / \mathrm{ml}$.

Peripheral blood NK cells were negatively selected from PBMCs by magnetic sorting using the Mini MACS NK isolation kit (Miltenyi Biotech, Shanghai, China). Isolated NK cells were activated by phytohemagglutinin (PHA;10 ng/ml; Sigma-Aldrich, St Louis, MO, USA) and IL-2 (1,000 IU/ml) in RPMI 1640 medium supplemented with $10 \%$ FCS.

\section{Isolation of exosomes from culture supernatants with or without MS-275}

The human HepG2 cell line (JCRB1054) was obtained from Beijing Cancer Research and Prevention Institute, Beijing, China. Cells were cultured in DMEM supplemented with 10\% FBS, $100 \mathrm{U} / \mathrm{ml}$ penicillin, and $100 \mu \mathrm{g} / \mathrm{ml}$ streptomycin at $37^{\circ} \mathrm{C}$ in an atmosphere of $5 \% \mathrm{CO}_{2} . \mathrm{MS}-275$ was purchased from Sigma-Aldrich.

Log phased HepG2 cells were plated into dishes at a density of $3 \times 10^{4} / \mathrm{ml}$. After 24-hour culture, MS-275 $\left(1 \times 10^{-6} \mathrm{~mol} / \mathrm{l}\right)$ was added. PBMCs treated with PHA served as the blank control. After incubation for 72 hours, culture media was collected and sequentially centrifuged at $300 \times \mathrm{g}$ at $4^{\circ} \mathrm{C}$ for 3 minutes, floating cells were removed, and then centrifuged at 2,000 $\times \mathrm{g}$ for 15 minutes at $4^{\circ} \mathrm{C}$ and at $12,000 \times \mathrm{g}$ at $4^{\circ} \mathrm{C}$ for 35 minutes. Cell debris was then removed. Supernatants were collected and passed through a $0.22 \mu \mathrm{m}$ filter. Exosomes were isolated by ultra-centrifugation at $120,000 \times \mathrm{g}$ at $4^{\circ} \mathrm{C}$ for 2 hours, and quantified by measuring their protein concentration with a BCA assay $(\mu \mathrm{g} / \mathrm{ml})$. Exosomes pellets were stored at $-80^{\circ} \mathrm{C}$ until use.

\section{Electron microscopic characterization and immunogold labeling of exosomes}

A total of 20 to $30 \mu$ prepared exosomes were loaded onto a copper net. Following air drying, $30 \mu \mathrm{l}$ phosphotungstic acid solution ( $\mathrm{pH} 6.8,20 \mathrm{ml} / \mathrm{l})$ was added and a negative staining was performed at room temperature for 1 minute. After drying at room temperature about 10 minutes, staining signals of the microcapsule membrane structure (30 to $80 \mathrm{~nm}$ ) were observed under a photographic transmission electron microscope.

For immunogold labeling, exosomes were applied to formvar carbon-coated copper grids and incubated with rabbit anti-human heat shock protein (HSP)70 monoclonal antibody (1:50 diluted, StressGen Biotechnologies Corporation, British Columbia, Canada), rabbit antihuman anti-major histocompatibility complex (MHC) class I polypeptide-related sequence A (MICA) antibody and rabbit anti-human anti-MICB monoclonal antibody (1:100 diluted, Biolegend, Sandiego, CA, USA), respectively, at room temperature for 1 hour. Incubation with PBS served as a blank control. Following washing in PBS, exosomes were incubated with $20 \mu \mathrm{l}$ protein A immunogold (SPA) (1:15 diluted) at room temperature for 30 minutes. A negative dye containing $15 \mu$ l uranyl acetate was performed at room temperature for $30 \mathrm{sec}-$ onds. Positively labeled exosomes were seen as vesicles containing black colloidal gold particles under the transmission electron microscope. The numbers of exosomes were counted in 10 random fields $(1000 \mathrm{~nm} \times 700 \mathrm{~nm})$. Counting was repeated five times and the average was calculated for each of the specimens.

\section{${ }^{3} \mathrm{H}-\mathrm{TdR}$ incorporation assay of peripheral blood mononuclear cell proliferation}

PBMCs were plated into a 96-well plate at a concentration of 5,000 cells/well in RPMI 1640 medium supplemented with $10 \%$ FBS; streptomycin and penicillin were added at a final concentration of $50 \mu \mathrm{g} / \mathrm{l}$ with or without PHA $(100 \mu$ loaded). In total, three groups were involved. The wells without exosomes served as controls, and the other two groups had either normal exosomes added or exosomes modified with MS-275, respectively (final exosome concentration $10 \mu \mathrm{g} / \mathrm{ml}$ ). After culture at $37^{\circ} \mathrm{C}$ in an atmosphere of $5 \% \mathrm{CO}_{2}$ overnight, $\mathrm{H}^{3}-\mathrm{TdR}$ was added to each well at a concentration of $3.7 \times 10^{4} \mathrm{~Bq}$. Following an incubation for 6 hours, $1 \mathrm{~mol} / \mathrm{l} \mathrm{NaOH}$ was used to break the cell membrane. Scintillation fluid and the quenching agent were added, and the $\mathrm{H}^{3}$-TdR incorporation was quantified as counts per minute (CPM) on a beta liquid scintillation counter (PerkinElmer Life Sciences, Waltham, MA, USA). 


\section{RNA isolation and RT-PCR}

After incubation with MS-275 for 3 days, HepG2 cells were washed and prepared for analysis. Total RNA was isolated using the RNeasy Micro Kit (Qiagen, Hilden, Germany). Single-strand cDNA was synthesized and HSP70, MICA and MICB were amplified using the following specific primers (Eurofins MWG Operon, Ebersberg, Germany): HSP70 forward 5'-TGTGG CTTCCTTCGTTATTGG-3' and reverse 5'-GCCAG CATCATTCACCACCAT-3'; MICA sense, 5' -CAGGG ACTTGACAGGGAAC-3' and antisense, $5^{\prime}$-CCTCTCC TCGGCAAATCCT-3'; MICB sense, 5'-ACCGAGGAC TTGACAGAGA-3' and antisense, $5^{\prime}$-CCGCTGATG TTTTC CTTCT-3'; and reverse: $5^{\prime}$-CACCTTGCCGT GTTGGAA-3' GAPDH forward: 5' -CCACTCCTCCAC CTTTGAC-3' and reverse: 5'-ACCCTGTTGCTG TAGCCA-3'. The PCR products were separated on $2 \%$ agarose gel and visualized with ethidium bromide. GADPH served as a control.

\section{Western blotting analysis}

Protein electrophoresis was performed as previously described [15]. After transfer, membrane blots were stained with Ponceau $S$ to verify quality of transfer and equal loading. Blots were probed for HSP70 and MICA and MICB using primary anti-HSP70 (1:500, StressGen) and MICA and MICB (Santa Cruz Biotechnology, Santa Cruz, CA) antibodies, respectively; horseradish peroxidase-conjugated anti-goat served as a secondary antibody (Amersham/ GE, Piscataway, NJ, USA). Specific immunoreactive signals were developed with a chemiluminescent agent (Pierce, Rockford, IL, USA). Densitometric analysis was performed as previously described [16].

\section{Cytotoxicity assay}

An AlamarBlue based one-step fluorimetric assay was performed as previously described [17]. Briefly, prepared normal exsomes and MS-275 modified exosomes $(10 \mu \mathrm{g} / \mathrm{ml})$ were added to the target HepG2 cells in 96-well flatbottomed plates, and effector cells (NK cells) were added; mixed effector and target cells were at ratios of 1:5, 1:10, $1: 20$, and 1:40, respectively. The mixtures were incubated with AlamarBlue in a humidified environment with $5 \%$ $\mathrm{CO}_{2}$ at $37^{\circ} \mathrm{C}$ overnight. The fluorescent signals of the AlamarBlue were read by a Synergy HT plate reader (Biotek, Winooski, VT, USA) at excitation of $530 \mathrm{~nm}$ and emission of $590 \mathrm{~nm}$, respectively. The cytotoxicity of NK cell was calculated using the following formula: where AF is the average fluorescence units.

\section{Statistical analysis}

Data were analyzed by chi-square test using SPSS 19.0 software IBM, Chicago, IL, USA. Differences were considered significant at $P<0.05$.

\section{Results and discussion}

\section{Electron microscopic characteristics of exosomes}

The exosomes secreted from HepG2 cells were round or oval membrane microcapsules with a diameter of 30 to $80 \mathrm{~nm}$ when observed under an electron microscope; the composition within the membrane showed a low electronic density (Figure 1A). We counted the average exosome number treated with or without MS-275, and the exosomes secreted by HepG2 cells increased greatly $(P<0.05)$ after treatment with MS-275 (Figure 1B). The immunogold labeling showed black granular colloidal gold signals existed in the capsular membrane and cavity. Compared with untreated HepG2 cells, MS-275treated HepG2 cells expressed significantly higher $(P<$ 0.001) levels of HSP70 and MICB-positive colloidal gold particles in exosomes (Figure 2); although we observed relative high levels of MICA after treatment with MS275 , there was no difference when compared with untreated exosomes. In untreated cells, the number of HSP70-positive colloidal gold particles was much higher than MICA- and MICB-positive particles.

\section{Effect of MS-275 on peripheral blood mononuclear cell proliferation}

The CPM value decreased in the exosomes modified by drug group $(19,411 \pm 786.63)$ when compared with the value in the blank control group $(23,974 \pm 2,024.31)$, but the difference between these two groups failed to reach a significant level $(P>0.05)$. In contrast, the CPM value was decreased significantly in the group of exosomes without drug modification $(3,863 \pm 20.88)$ when compared with the value in the blank control group $(P<0.001)$ and the exosomes modified by drug group $(P<0.05)$.

\section{MS-275 induced elevated expression of heat shock protein 70, MICA, and MICB in hepatoma G2 cells} After treatment with MS-275, the mRNA expression of HSP70, MICA, and MICB were all upregulated in HepG2 cells, compared to cells without treatment by MS-275. The relative expression of HSP70, MICA, and

NK cell cytotoxicity $(\%)=(\mathrm{AF}$ of observation group-AF of target cells-AF of effector cells $) /$

(AF of fully lysis target cells-AF of target cells) $\times 100 \%$ 


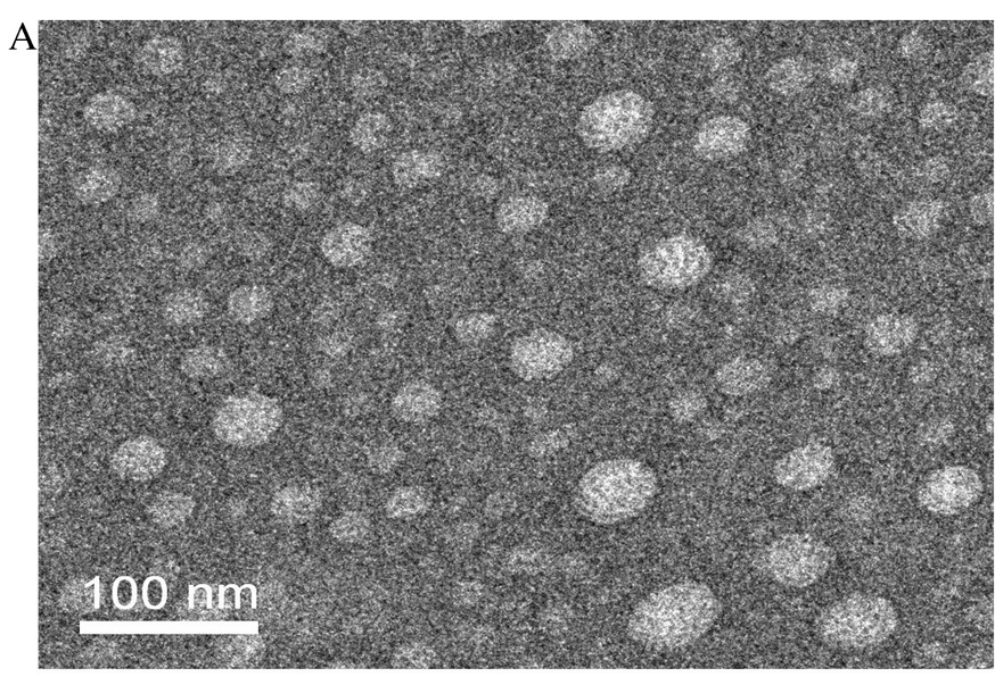

$\mathrm{B}$

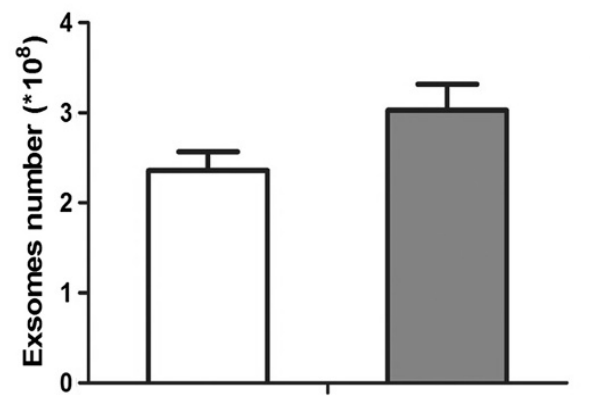

Cell treated without drug

Cell treatedby drug

Figure 1 The electron microscope observation result of exosomes secreted from hepatoma G2 cells. (A) The microcapsule of exosomes have a diameter of 30 to $80 \mathrm{~nm}$. (B) Column comparison of exosome expression with or without MS-275.

MICB was upregulated by 3.4-, 3.6- and 2.8-fold, respectively (Figure 3 ).

\section{Western blotting analysis results}

Consistent with mRNA expression, western blotting analysis showed the specific protein bands of HSP70
(147 kDa), MICA $(73 \mathrm{kDa})$ and $\mathrm{MICB}(47 \mathrm{kDa})$ in the HepG2 cell-derived exosomes (Figure 4). MS275 modification significantly increased MICB and HSP70 protein in the exosomes of HepG2 cells compared to those without MS-275 treatment $(P<0.05)$.

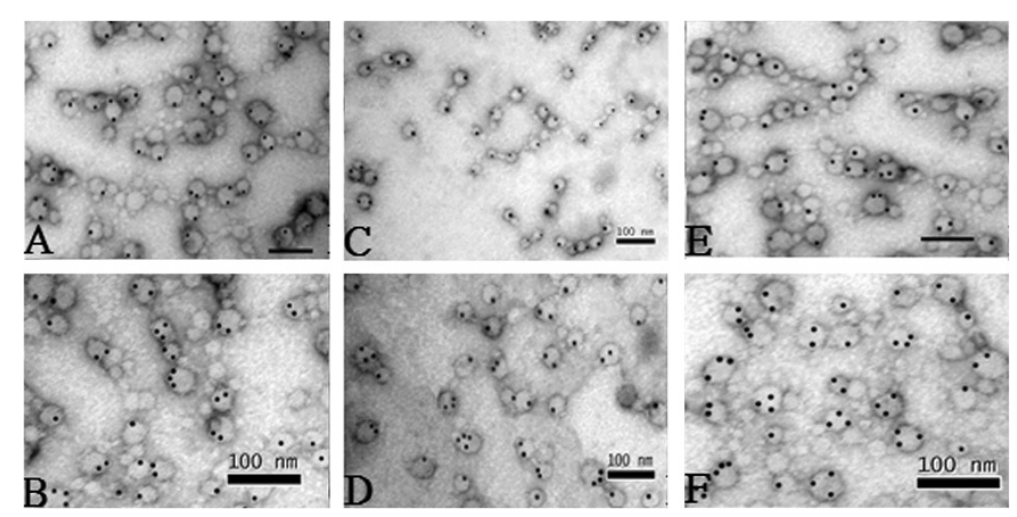

Figure 2 The comparison of immunogold labeling of hepatoma G2 cells treated with or without MS-275. After treatment with MS-275, heat shock protein (HSP)70, MICA, and MICB molecular colloidal gold particles increased in exosomes with statistical significance

$(P<0.01)$. (A) HSP70 protein without drug. (B) HSP70 protein treated with drug. (C) MICA protein without drug. (D) MICA protein treated with drug. (E) MICB protein without drug. (F) MICB protein treated with drug. 


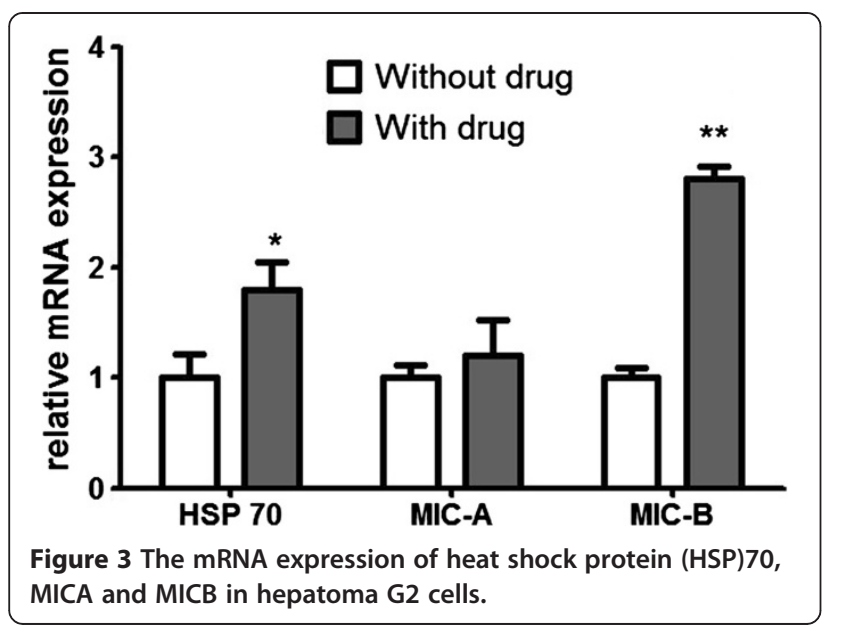

Natural killer cell cytotoxicity

We evaluated the cytotoxicity of NK cells against HepG2 cells at various NK/HepG2 cell ratios with normal or MS-275 modified exosomes. The results are presented in Table 1. As the NK/HepG2 cell ratio increased, the dead HepG2 cells increased. MS-275 significantly

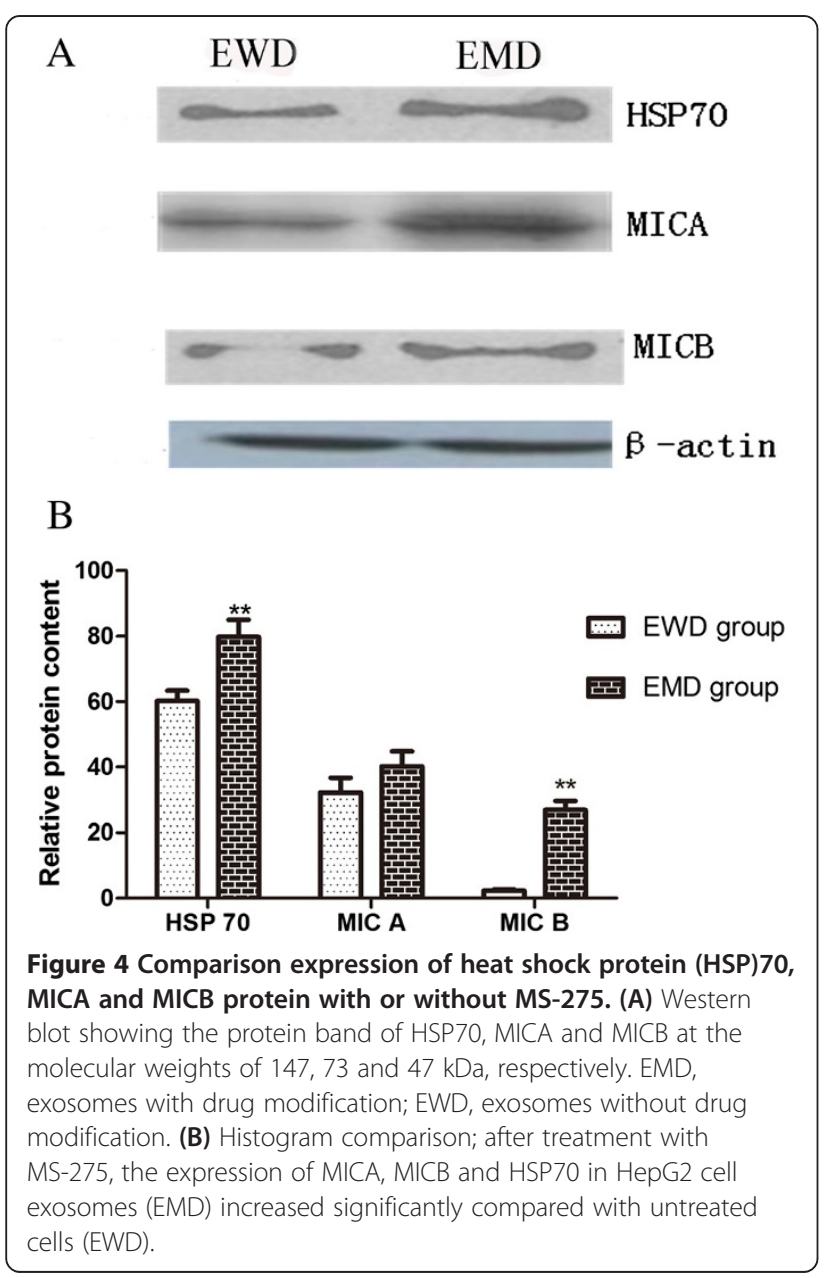

Table 1 Percentage of hepatoma G2 cells killed by natural killer cells at various effector: target cell ratios with or without MS-275 modification

\begin{tabular}{lllll}
\hline & \multicolumn{4}{l}{ Effector cell (NK cells): target cell ratios } \\
\cline { 2 - 5 } & $\mathbf{5 : 1}$ & $\mathbf{1 0 : 1}$ & $\mathbf{2 0 : 1}$ & $\mathbf{4 0 : 1}$ \\
\hline EWD group (\%) & $1.69 \pm 0.13$ & $2.47 \pm 0.84$ & $5.21 \pm 1.07$ & $5.77 \pm 0.83$ \\
EMD group (\%) & $25.32 \pm 1.31^{*}$ & $42.27 \pm 1.67^{*}$ & $57.53 \pm 2.13^{*}$ & $70.21 \pm 3.01^{*}$ \\
\hline
\end{tabular}

${ }^{*} P<0.05$ compared with EWD group. EMD: exosomes with drug modification; EWD, exosomes without drug modification; NK, natural killer.

increased the cytotoxicity of NK cells at the same effector/target cell ratio $(P<0.05)$.

Exosomes are vesicles formed by 'inward/reverse budding' of the limiting membrane of the multivesicular bodies in the late endocytic compartment that are released upon the fusion of multivesicular bodies with the plasma membrane $[18,19]$. Exosome proteins derived from the tumor cell membrane are rich in tumor antigen chaperone molecules such as HSP70, 80, 90 and MHC class I molecules. HSP70 originated from tumor exosomes can selectively activate NK cell activity, thus leading to the migration and proliferation of tumor cell and augmentation of an immune response [20]. Due to their molecular chaperone properties, HSPs can bind tumorspecific peptides and deliver them deep into the antigenprocessing pathways of antigen-presenting cells. In this way, HSP-based vaccines can activate tumor-specific immunity, trigger the proliferation and cytotoxic $\mathrm{T}$ lymphocyte capabilities of cancer-specific $\mathrm{CD}^{+} \mathrm{T}$ cells, and inhibit tumor growth [21]. However, the immune stimulatory activity of exosomes in tumor cells is dependent on their expression level. Moreover, tumorderived exosomes lack antigen presentation stimulators such as T-cell-activating protein, latent membrane protein and Tapasin; as a result, their tumor immunosuppressive activity is substantially compromised [22].

The extent of exosome secretion in different cell types can be modulated by either ligand cognition or stresses. For example, radiation treatment is able to increase the level of exosomes secreted by tumor cells, a process possibly involving the activation of p53 and the subsequent upregulation of the trans-membrane protein tumor suppressor-activated pathway 6 [23,24]. HDACi exert their effects predominantly by altering histone acetylation, which is normally controlled by a balance between histone deacetylases and histone acetyltransferases [25]. Increased histone acetylation induced by HDACi results in activation of the genes responsible for: 1) generating an intracellular pro-apoptotic milieu [26], 2) increasing surface expression of TNF, super-family death receptors like Fas, TNF-related apoptosis-inducing receptor and TNFreceptors [27], 3) increasing the expression of MHC molecules and other molecules involved in antigen processing and presentation [22,28], and 4) increasing expression of 
tumor antigens recognized by cytotoxic $\mathrm{T}$ lymphocytes and ligands for NK activating receptors [29].

In our study, we found MS-275 was able to increase the secretion of MICB and HSP70 in exosomes secreted by HepG2 cells significantly. We also observed that MS275 modification could attenuate the inhibitory effect of naive exosomes on the cytotoxicity of NK cells, possibly through upregulating the expression of the MICA, MICB, and HSP70 on the tumor cell surface. These observations were consistent with the results of electron microscopic assessment.

\section{Conclusion}

In conclusion, soluble immunoregulatory molecules in the exosomes secreted by HepG2 cells have a significant inhibitory effect on lymphocyte proliferation. MS-275 modified exosomes enhance the cytotoxic effect of NK cells significantly through upregulating the expression of MICA, MICB and HSP70. Our observations suggest that HDACi-modified tumor cell-derived exosomes may function as potential tumor vaccines against liver cancer. We only observed one HDACi drug (MS-275) and one tumor cell line (HepG2); therefore, it is difficult to conclude that this conclusion is universally represented. An in-depth study is therefore needed, but our study can provide some reference for similar research.

\footnotetext{
Abbreviations

CPM: Counts per minute; DMEM: Dulbecco's modified Eagle's medium; FBS: Fetal bovine serum; FCS: Fetal calf serum; HDACi: histone deacetylase inhibitor; HepG2: Hepatoma G2; HSP: heat shock protein; IL: Interleukin; MHC: Major histocompatibility complex; MICA: MHC class I polypeptide-related sequence A; MICB: MHC class I polypeptide-related sequence B; NK: natural killer; PBMC: Peripheral blood mononuclear cell; PBS: Phosphate-buffered saline; PHA: Phytohemagglutinin; RT-PCR: Reverse transcriptase polymerase chain reaction; TNF: Tumor necrosis factor.
}

\section{Competing interests}

The authors declare that they have no competing interests.

\section{Authors' contributions}

WX and CZ defined the research theme. GS and PG designed methods and experiments, carried out the laboratory experiments, analyzed the data, and interpreted the results. $\mathrm{HZ}$ and WD co-designed the dispersal and colonization experiments. QL and JZ co-worked on associated data collection and their interpretation. GL, SZ and MY co-designed experiments, discussed analyses, interpretation, and presentation. All authors read and approved the final manuscript.

\section{Acknowledgement}

We thank our colleagues in our hospital for the support given.

\section{Author details}

${ }^{1}$ The First Affiliated Hospital, PLA General Hospital, Fucheng Road 51, Beijing, China. ${ }^{2}$ Department of Immunology, Medical College of Qinghai University, No.16 Kunlun Road, Xining 810001, Qinghai Province, China. ${ }^{3}$ Department of Histology and Embryology, Inner Mongolia Medial College, Inner Mogolia Autonomous Region, Hohhot 010010, China.

Received: 21 September 2013 Accepted: 25 November 2013

Published: 23 December 2013

\section{References}

1. Simhadri VR, Reiners KS, Hansen HP, Topolar D, Simhadri VL, Nohroudi K, Kufer TA, Engert A, Pogge von Strandmann E: Dendritic cells release HLA-B-associated transcript-3 positive exosomes to regulate natural killer function. PLOS One 2008, 3:e3377

2. Bhat SP, Gangalum RK: Secretion of alphaB-Crystallin via exosomes: new clues to the function of human retinal pigment epithelium. Commun Integr Biol 2011, 4:739-741.

3. Chalmin F, Ladoire S, Mignot G, Vincent J, Bruchard M, Remy-Martin JP, Boireau W, Rouleau A, Simon B, Lanneau D, et al: Membrane-associated Hsp72 from tumor-derived exosomes mediates STAT3-dependent immunosuppressive function of mouse and human myeloid-derived suppressor cells. J Clin Invest 2010, 120:457-471.

4. Valadi H, Ekstrom K, Bossios A, Sjostrand M, Lee JJ, Lotvall JO: Exosomemediated transfer of mRNAs and microRNAs is a novel mechanism of genetic exchange between cells. Nat Cell Biol 2007, 9:654-659.

5. Thery C, Boussac M, Veron P, Ricciardi-Castagnoli P, Raposo G, Garin J, Amigorena S: Proteomic analysis of dendritic cell-derived exosomes: a secreted subcellular compartment distinct from apoptotic vesicles. $\mathrm{J}$ Immunol 2001, 166:7309-7318.

6. Fevrier B, Vilette D, Archer F, Loew D, Faigle W, Vidal M, Laude H, Raposo G: Cells release prions in association with exosomes. Proc Natl Acad Sci USA 2004, 101:9683-9688.

7. Lee HD, Koo BH, Kim YH, Jeon OH, Kim DS: Exosome release of ADAM15 and the functional implications of human macrophage-derived ADAM15 exosomes. FASEB J 2012, 26:3084-3095.

8. Battke C, Ruiss R, Welsch U, Wimberger P, Lang S, Jochum S, Zeidler R: Tumour exosomes inhibit binding of tumour-reactive antibodies to tumour cells and reduce ADCC. Cancer Immunol Immunother 2011, 60:639-648.

9. Kahlert C, Kalluri R: Exosomes in tumor microenvironment influence cancer progression and metastasis. J Mol Med 2013, 91:431-437.

10. Yang C, Kim SH, Bianco NR, Robbins PD: Tumor-derived exosomes confer antigen-specific immunosuppression in a murine delayed-type hypersensitivity model. PLoS One 2011, 6:e22517.

11. Quah B, O'Neill HC: Review: the application of dendritic cell-derived exosomes in tumour immunotherapy. Cancer Biother Radiopharm 2000, 15:185-194.

12. Qu JL, Qu XJ, Zhao MF, Teng YE, Zhang Y, Hou KZ, Jiang YH, Yang XH, Liu YP: Gastric cancer exosomes promote tumour cell proliferation through PI3K/Akt and MAPK/ERK activation. Dig Liver Dis 2009, 41:875-880.

13. Keller S, Konig AK, Marme F, Runz S, Wolterink S, Koensgen D, Mustea A, Sehouli J, Altevogt P: Systemic presence and tumor-growth promoting effect of ovarian carcinoma released exosomes. Cancer Lett 2009, 278:73-81.

14. Vissers MC, Jester SA, Fantone JC: Rapid purification of human peripheral blood monocytes by centrifugation through Ficoll-Hypaque and Sepracell-MN. J Immunol Methods 1988, 110:203-207.

15. Lancaster Gl, Febbraio MA: Exosome-dependent trafficking of HSP70: a novel secretory pathway for cellular stress proteins. J Biol Chem 2005, 280:23349-23355.

16. Nakano M, Mann DL, Knowlton AA: Blocking the endogenous increase in HSP 72 increases susceptibility to hypoxia and reoxygenation in isolated adult feline cardiocytes. Circulation 1997, 95:1523-1531.

17. Schleger C, Platz SJ, Deschl U: Development of an in vitro model for vascular injury with human endothelial cells. Altex 2004, 21(Suppl 3):12-19.

18. Denzer K, Kleijmeer MJ, Heijnen HF, Stoorvogel W, Geuze HJ: Exosome: from internal vesicle of the multivesicular body to intercellular signaling device. J Cell Sci 2000, 113:3365-3374.

19. Stoorvogel W, Kleijmeer MJ, Geuze HJ, Raposo G: The biogenesis and functions of exosomes. Traffic 2002, 3:321-330.

20. Clayton A, Mitchell JP, Court J, Mason MD, Tabi Z: Human tumor-derived exosomes selectively impair lymphocyte responses to interleukin-2. Cancer Res 2007, 67:7458-7466.

21. Calderwood SK, Stevenson MA, Murshid A: Heat shock proteins, autoimmunity, and cancer treatment. Autoimmun Dis 2012, 2012:486069.

22. Setiadi AF, Omilusik K, David MD, Seipp RP, Hartikainen J, Gopaul R, Choi KB, Jefferies WA: Epigenetic enhancement of antigen processing and presentation promotes immune recognition of tumors. Cancer Res 2008 68:9601-9607 
23. Lespagnol A, Duflaut D, Beekman C, Blanc L, Fiucci G, Marine JC, Vidal M, Amson R, Telerman A: Exosome secretion, including the DNA damageinduced p53-dependent secretory pathway, is severely compromised in TSAP6/Steap3-null mice. Cell Death Differ 2008, 15:1723-1733.

24. Yu X, Harris SL, Levine AJ: The regulation of exosome secretion: a novel function of the p53 protein. Cancer Res 2006, 66:4795-4801.

25. Deubzer HE, Ehemann V, Kulozik AE, Westermann F, Savelyeva L, Kopp-Schneider A, Riester D, Schwab M, Witt O: Anti-neuroblastoma activity of Helminthosporium carbonum (HC)-toxin is superior to that of other differentiating compounds in vitro. Cancer Lett 2008, 264:21-28.

26. Peart MJ, Smyth GK, van Laar RK, Bowtell DD, Richon VM, Marks PA, Holloway AJ, Johnstone RW: Identification and functional significance of genes regulated by structurally different histone deacetylase inhibitors. Proc Natl Acad Sci U S A 2005, 102:3697-3702.

27. Insinga A, Monestiroli S, Ronzoni S, Gelmetti V, Marchesi F, Viale A, Altucci L, Nervi C, Minucci S, Pelicci PG: Inhibitors of histone deacetylases induce tumor-selective apoptosis through activation of the death receptor pathway. Nat Med 2005, 11:71-76.

28. Khan AN, Gregorie CJ, Tomasi TB: Histone deacetylase inhibitors induce TAP, LMP, Tapasin genes and MHC class I antigen presentation by melanoma cells. Cancer Immunol Immunother 2008, 57:647-654.

29. Thielens A, Vivier E, Romagne F: NK cell MHC class I specific receptors (KIR): from biology to clinical intervention. Curr Opin Immunol 2012, 24:239-245.

doi:10.1186/2047-783X-18-61

Cite this article as: Xiao et al.: Effects of the epigenetic drug MS-275 on the release and function of exosome-related immune molecules in hepatocellular carcinoma cells. European Journal of Medical Research 2014 18:61.

\section{Submit your next manuscript to BioMed Central and take full advantage of:}

- Convenient online submission

- Thorough peer review

- No space constraints or color figure charges

- Immediate publication on acceptance

- Inclusion in PubMed, CAS, Scopus and Google Scholar

- Research which is freely available for redistribution 